\title{
Adaptation of the Australian Palliative Care Phase concept to the German palliative care context: a mixed-methods approach using cognitive interviews and cross-sectional data
}

\author{
Eva Lehmann ${ }^{1 *}$, Farina Hodiamont ${ }^{1}$, Mirjam Landmesser ${ }^{2}$, Carina S. Knobloch ${ }^{3}$, Friedemann Nauck ${ }^{2}$, \\ Christoph Ostgathe ${ }^{3}$, Bettina Grüne ${ }^{1 \dagger}$ and Claudia Bausewein ${ }^{1 \dagger}$
}

\begin{abstract}
Background: Palliative care phases (stable, unstable, deteriorating, terminal and bereavement) are routinely used in Australia and the UK to describe the clinical situation of patients and their families and to evaluate the associated care plan. In addition, it serves as a benchmark developed by the Australian Palliative Care Outcome Collaboration (PCOC) and is used nationwide for comparisons between services. In Germany, the concept is not used consistently due to various translations. Furthermore, there is no nationwide systematic approach to routinely assess clinical outcomes in palliative care.

The study aims to develop a German version of the palliative care phase definitions by adapting them culturally, and to examine the inter-rater reliability of the adjusted definitions with healthcare professionals.

Methods: Mixed-methods approach: Cognitive interview study using 'think aloud' and verbal probing techniques and a consecutive multi-center cross-sectional study with two clinicians independently assigning the phase definitions. Interviewees/participants were selected through convenience and purposive sampling in specialist palliative care inpatient units, advisory and community services and in three specialist palliative care units with doctors, nursing staff and allied health professionals.
\end{abstract}

Results: Fifteen interviews were conducted. Identified difficulties were: Some translated terms were 1) not selfexplanatory (e.g. 'family/carer' or 'care plan') and (2) too limited to the medical dimension neglecting the holistic approach of palliative care. (3) Problems of comprehension regarding the concept in general occurred, e.g. in differentiating between the 'unstable' and 'deteriorating' phase. Inter-rater reliability was moderate (kappa $=0.44 ; 95 \%$ $\mathrm{Cl}=0.39-0.52)$. The assignment of the phase 'deteriorating' has caused the most difficulties.

Conclusion: Overall, the adapted palliative care phases are suitable to use in the German specialist palliative care setting. However, the concept of the phases is not self-explanatory. To implement it nationwide for outcome measurement/benchmarking, it requires further education, on-the-job training and experience as well as the involvement

\footnotetext{
*Correspondence: eva.lehmann@med.uni-muenchen.de

†Bettina Grüne and Claudia Bausewein contributed equally to this work.

1 Department, of Palliative Medicine, University Hospital, LMU Munich,

Marchioninistr. 15, 81377 Munich, Germany

Full list of author information is available at the end of the article
}

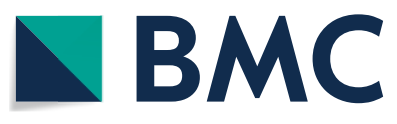

(c) The Author(s) 2021. Open Access This article is licensed under a Creative Commons Attribution 4.0 International License, which permits use, sharing, adaptation, distribution and reproduction in any medium or format, as long as you give appropriate credit to the original author(s) and the source, provide a link to the Creative Commons licence, and indicate if changes were made. The images or other third party material in this article are included in the article's Creative Commons licence, unless indicated otherwise in a credit line to the material. If material is not included in the article's Creative Commons licence and your intended use is not permitted by statutory regulation or exceeds the permitted use, you will need to obtain permission directly from the copyright holder. To view a copy of this licence, visit http://creativecommons.org/licenses/by/4.0/. The Creative Commons Public Domain Dedication waiver (http://creativeco mmons.org/publicdomain/zero/1.0/) applies to the data made available in this article, unless otherwise stated in a credit line to the data. 
of healthcare professionals in implementation process. For the use of international concepts in different healthcare systems, a deeper discussion and cultural adaptation is necessary besides the formal translation.

Keywords: Palliative care phases, Palliative care, Cognitive interviewing, Inter-rater reliability, Reproducibility of results, Outcome measurement, Quality of healthcare

\section{Background}

The care of seriously ill patients by specialist palliative care may become necessary if the patients' situation proves to be complex and thus particularly resourceintensive [1]. The extent of the complexity of a care situation is determined by the intensity of individual symptom burden and/or psychosocial, spiritual or ethical problems of the patients as well as their simultaneous occurrence and interaction [2]. Studies from Australia and UK use clinical assessment tools to describe the complexity of the patient's situation, which map the areas of severity of symptoms and problems, performance of activities of daily living and functional status, as well as the burden on relatives $[2,3]$. Clinical assessment tools are standardised and validated instruments that provide the palliative care team with relevant information about the condition/situation of patients and their relatives. Either the assessment tools are completed by the patients themselves, or they are assessed by the treating palliative care team [4-6]. Therefore, the use of assessment tools influences the identification of needs, the monitoring of symptoms and the implementation of clinical interventions. Furthermore, it influences the communication between patients and doctors and leads to an improvement of patient outcomes through person-centred care [4, 7-9].

The concept 'Palliative Care Phase' is a clinical assessment tool which is increasingly in use since its development by the Australian Association for Hospice and Palliative Care in 1993 [10]. It was first tested and revised in 1994 [11] and for a second time in 2011 [12]. The concept includes five phases: 'stable', 'unstable', 'deteriorating,' 'terminal' and 'bereavement'. They describe the clinical situation of patients and their families as well as related care needs and the suitability of the current care plan. The concept is based on the principle that patients and their carers form the unit of care. Palliative care phase focuses on individual needs, goals and priorities rather than on the disease itself [12]. A phase changes when the existing care plan is no longer effective. Palliative care phases do not have a linear trajectory due to the unpredictable progression of incurable diseases and patients' individual goals and needs. Therefore, phases can alternate and occur several times [12, 13]. In inpatient care in Australia, an average of two phases per patient was reported $[14,15]$.
Palliative care phase are significantly associated with functional status and have been proven to be an indicator of palliative needs: mean function was lowest in the terminal phase and highest in the stable phase; mean pain was highest in the unstable phase, family and carer support needs were lowest in the stable phase $[13,16]$. Due to the strong association with resource use, they play a key role in the Australian casemix classification [2, 17]. Additionally, palliative care phase is embedded in nationwide routine clinical outcome measurement of specialist palliative care in Australia (since 2005) [12] and the UK (since 2013) [18]. Within these routine assessments, it has been shown that palliative care phase has benefits in everyday care. It provides a common language in the multi-professional team, facilitates care planning, serves to prioritise treatment and, thus, supports clinical decision making [16]. Palliative care phase is also used for monitoring and assurance of quality of care. The duration of the unstable phase is considered to be a quality indicator for palliative care services $[12-14,19]$. Moreover, it is one of the national benchmarks developed by Palliative Care Outcome Collaboration (PCOC) since 2009 and is used for comparisons between services to develop areas for improvement and support services in improving their practice $[16,20]$.

For further quality improvement and to facilitate international benchmarking, a uniform approach regarding outcome measurement across palliative care services is needed. De Wolf-Linder et al. (2019) recommend using palliative care phases as the temporal indicator for these measurements in specialist palliative care. It is seen as a key element providing information on the severity and urgency of patient needs, but needs to be further improved in terms of education, context and consistency [19].

In Germany, the national guideline on palliative care for patients with incurable cancer advices that generalist or specialist palliative care has to be involved in the treatment depending on the complexity of the patient's needs [21]. However, no evidence based system exists to differentiate the complexity of patients' needs and care demands [22]. Moreover, there is no nationwide systematic approach to routinely assess clinical outcomes in palliative care. Additionally, there is an increasing demand for high quality care and monitoring of resource use by healthcare insurances and service providers. 
Palliative care phase seems to be the appropriate instrument to assess needs as well as to provide information on resource use and quality of care.

In Germany, routine outcome measurement in the clinical setting is used in some services but is not yet widely implemented. Similarly, few services use the palliative care phases both in the inpatient and home care setting. However, no data on palliative care phases or research on phases is available in Germany. Therefore, the aim of this study was to develop a culturally adapted German version of the Australian palliative care phase definitions. The objectives were i) to gain a deeper understanding of the meaning and comprehensibility of the translated phase definitions in different specialist palliative care settings in Germany and ii) to examine the inter-rater reliability of the developed instrument in German palliative care.

\section{Methods}

Design

Sequential mixed-methods design:

i) Cross-sectional multi-centre qualitative interview study using several rounds of cognitive interviews.

ii) Multi-centre cross-sectional study, pairs of clinicians rating patients independently applying the revised definitions of palliative care phase.

The COREQ checklist was applied to the first part of the study and the STROBE statement to the second part $[23,24]$ (Additional file 1).

\section{Cognitive interviews \\ Setting and participants}

To include a variety of views and experiences, convenience and purposive sampling was based on a sampling frame (Additional file 2) including professional groups (doctors, nursing staff and allied health professionals), gender and setting [25]. Participants were recruited personally, by email or phone in all specialist palliative care settings: palliative care unit, palliative care advisory team, and specialist palliative home care.

\section{Data collection and analysis}

The Australian phase definitions were translated independently and compared and revised by two research associates. To evaluate how palliative care phases are understood and where difficulties may arise we used cognitive interviewing, that is usually applied to evaluate the understanding of questions in surveys [26] We developed an interview guide (Additional file 3) according to Beatty and Willis which contained instructions to think aloud technique as well as probing questions [27]
The interviewees were asked to 'think aloud' while reading each phase definition out loud. Afterwards, they were asked what they understood and how they interpreted it [26] Specific questions were asked about the understanding of individual words/statements to generate more verbal information. Additional probing questions could be addressed, to explore verbal or non-verbal expressions such as hesitation or irritation [27].

The first two interviews were used for pilot testing the interview guide, which was approved. The following interviews were conducted iteratively in three rounds, as recommended [28]. Interviews were audio recorded. Audio records were transcribed verbatim and analysed using a systematizing qualitative analysis approach following Knafl and colleagues: They use an item-by-item analysis with a focus on how participants understood the survey questions and were able and willing to respond. Results supported decision-making for keeping, deleting or changing terms or phrases [26]. Accordingly, terms and phrases that were understandable and consistently interpreted by all participants were kept, others were modified or deleted. Data analysis was also conducted in three rounds. In order to standardise the analysis, EL and BG deductively developed a coding scheme, based on the research questions and the interview guide. The revision of the phase definitions was made (by EL, BG and $\mathrm{CB})$ to be tested in the next round. The interview guide was adapted accordingly. Due to less substantive remarks and more layout and formalities in the third round, data saturation was assumed and the phase definitions were revised finally. $20 \%$ of all material was double coded. The qualitative data management software MaxQDA was used to support analysis. In total, between January and April 2020, ten interviews were conducted in a place chosen by the participants and five by phone due to the COVID-19 pandemic. In the case of interviews conducted by phone, the phase descriptions were sent to the interviewees in advance by email so that they had them at hand. The interview process had otherwise not changed.

\section{Cross-sectional study}

The approach of the second part of the study is following the work of Masso et al. [12] in Australia.

\section{Setting and participants}

The study involved three different specialist palliative care units in university hospitals in Germany. None of the services routinely collected palliative care phases prior to the study. Only one service collected data on palliative care phases sporadically for over 2 years. The concept and an accompanying manual were presented to all services with video tutorials. All members of the 
multi-professional teams were invited to participate in the study (doctors, nurses, allied health professionals).

\section{Data collection}

Two participants were asked to independently assign the palliative care phase to the same patient. The bereavement phase was excluded as it is clear to assign. Assignments had been made twice a week for all inpatients with at least two days apart, e.g. on Tuesday and Friday after the ward round/regular team meeting without any prior communication on palliative care phases. The independent assignments of one patient had to be completed within two hours. Multiple assignments of one patient on separate days were possible. These were connected via a patient-ID. Furthermore, indicators of acceptability were assessed with the following additional questions (on a 5 -point scale from $1-5$ ):

1. How appropriate is the definition of the assigned phase to describe the current situation of this patient? (1 'not appropriate' to 5 'very appropriate')

2. How difficult was it for you today to assign a phase to this patient? ( 1 'very difficult' to 5 'very easy')

3. How familiar are you with this patient and his/her situation? (1 'unfamiliar' to 5 'very familiar')

4. What other information about the assignment of the palliative care phase would you like to give us?

The comments in question 4 were analysed to identify uncertainties in the assignments. To describe the patient population, the following characteristics were collected: age, sex and the diagnosis (malignant or non-malignant). Professionals were asked about sociodemographic characteristics and clinical experience: age group, profession, sex, length of clinical experience in specialist palliative care and experience in assigning palliative care phases. These information were not linked with the assignments and only used for describing the sample. All participating services designated a responsible person for data collection who ensured adherence to the study protocol. Data collection took place from June to October 2020.

\section{Analysis}

For inter-rater reliability Cohen's Kappa was calculated. According to Landis and Koch (1977), kappa should be $0.61-0.80$ in order to assume a substantial agreement [29]. The sample size is determined based on (1) an assumed level of agreement of $\mathrm{k}=0.67$, which corresponds to the observed $\mathrm{k}$ in the Australian study [12], (2) the probability that professionals can observe and assess the individual phases (the prevalence of the individual phases was taken from the Australian PCOC organisation's National Report [30] published in September 2019 (stable: 25\%, unstable 19\%, deteriorating 35\%, dying 21\%) and (3) a target minimum correspondence of $\mathrm{k}=0.61$, which correlates to the lower limit of a 95\% confidence interval. The sample size was calculated with the package kappaSize in $\mathrm{R}$ (version 4.0.2). Under the given assumptions and objectives, a sample size of $n=300$ phase estimates was determined. Thus, each service should assign $\mathrm{n}=100$ palliative care phases.

Furthermore, agreement was calculated in percent and a descriptive analysis of the supplementary questions was conducted, stratified by phase, agreement/lack of agreement and institution. Comments were evaluated by content analysis. Cases with missing data in phase assignments were excluded from analysis.

\section{Results}

Cognitive interviews

Sample description

Fifteen interviews with a duration of 30 to $88 \mathrm{~min}$ were conducted. 15/16 persons accepted the invitation. One person did not respond. Table 1 gives the demographic details of the participants.

\section{Findings from the interviews and phase definition refinement}

Round 1 The first round was characterized by comments that were substantial to a proper understanding of the concept. Interviewees viewed the translations of the terms 'care plan' or'plan of care' as well as of the term 'emergency treatment' as inappropriate:

\section{'R: (...) By a treatment plan I would primarily understand a medical treatment plan. But prob-}

Table 1 Demographic details of the participants $(n=15)$

\begin{tabular}{|c|c|c|}
\hline & & $n=15$ \\
\hline \multirow[t]{4}{*}{ Age group (years) } & $25-29$ & 3 \\
\hline & $40-49$ & 6 \\
\hline & $50-59$ & 4 \\
\hline & 60 and older & 2 \\
\hline \multirow[t]{3}{*}{ Sex } & Female & 11 \\
\hline & Male & 4 \\
\hline & Other & 0 \\
\hline Work experience (years) & Median (range) & $10(1-20)$ \\
\hline \multirow[t]{3}{*}{ Care setting } & Palliative care unit (1) & 6 \\
\hline & Community palliative care team (2) & 4 \\
\hline & Palliative care advisory team (3) & 5 \\
\hline \multirow[t]{3}{*}{ Profession } & Doctors & 8 \\
\hline & Nurses & 4 \\
\hline & $\begin{array}{l}\text { Allied health professionals (psychol- } \\
\text { ogists, therapists, social workers) }\end{array}$ & 3 \\
\hline
\end{tabular}


ably that is not what is meant, probably the treatment plan (...) is meant in such a way that it does not only include medical procedures, medication or something, but also other supporting activities. \#00:04:56-6\# (Eva_doctor_3: 31).

'I: What do you understand by emergency treatment? \#00:10:01-8\#

R: Yes, an unplanned medical treatment. (...) But this is something that is only used in a medical context, emergency treatment, but under point three it's more like a psychosocial emergency.' \#00:10:45-4\# (Eva_doctor_3: 64-65).

Both were felt to be too limited to the medical dimension of care and to neglect the holistic approach of palliative care and its four dimensions (physical, psychological, social \& spiritual). For these reasons, the German translation was adapted to terms that focus on the holistic care perspective rather than the medical treatment perspective. For instance, in the case of 'emergency treatment' it was changed to 'emergency intervention'. The selected terms were tested in the following interview round and eventually integrated into the final version.

In addition, it became clear that the translations of some terms were not self-explanatory, for example the words 'family/carer' or 'family/carers circumstances'. In this context, the participants were asked what they understand by the terms 'family/carer' and what kind of experience they have concerning situations of relatives that may affect the care of patients. The role of the 'family/carer' can be fulfilled by actual family members, but also from informal caregivers, the community/neighbourhood network or nursing homes/outpatient care services. Answers regarding the circumstances possibly affecting care were for example massive burden, alienation/unresolved conflicts in the family, relatives' own illness/accident/death, financial difficulties and overburdening of nursing homes or outpatient care services.

Furthermore, the term 'functional status' was perceived as too technical and it was suggested to speak of 'general condition', as this is often used in communication with patients:

'R: Functional status, that sounds as if my car is broken or DAMAGED or/ (Laughs) (...) that is a very technical term (...) I would never use the word "functional status" when talking about a patient or a relative, because with that you reduce the person a bit. \#00:15:33-5\#
I: What term do you think of alternatively or what other term would you use then? \#00:15:39-1\#

R: Well, I would maybe say general condition, I think that's more appropriate.' \#00:16:28-2\# (Günther_nurse_1: 47-50)

Another essential comment in the first cycle of interviews was that the Australian description of the bereavement phase does not comply with the procedures in the German palliative care setting:

' $R$ : Yes, that closing of the patient case in the sense of support after DEATH (...) IS correct in relation to patient support. But I don't think it should be formulated so harshly (...) signal that we nevertheless also feel responsible for accompanying relatives with difficult grief work beyond death.' \#00:29:29-4\# (Claudia_doctor_3: 81).

Therefore, the description of the phase was shortened to the sentence 'the patient has died' and 'case closure.' The second round was used to collect more information on the procedures in the bereavement phase in the German specialist palliative care settings.

For reasons of clarity, the interviewees noted that they would prefer a consistent use of terms such as problem, symptom and crisis rather than using terms synonymously.

Round 2 Round two was used to verify the changes made after round one. All were assessed to be appropriate by those interviewed and were therefore retained. Furthermore, it was determined by collecting information about the bereavement phase which was reduced to basic information (see round 1). Participants wondered why relatives were not mentioned in this phase and stressed the importance of mentioning them due to the need of individual offers to support them in coping with grief.

'R: So deceased: grief counselling. The patient has passed away. And closure of the case in the care setting. (...) The relatives no longer appear now. (...) I miss them now. \#00:11:42-6\# (Inge_alliedhealth_1: 89-91)

Round 3 In the last round, fewer substantive remarks were made to the definitions. Instead, it was more about layout and formalities. One interviewee recommended to change the headings 'Start' and 'End' of the phase 
definitions into 'Phase' and 'Phase change' as these headings correspond much better to the subsequent texts:

\section{'R: Well, I would rather say, not beginning, but this is the phase, we are in the middle of it, what does phase 'stable' mean, what does phase 'unstable' mean. And then I wouldn't write end, but transition into other phases, and then describe that more con- cretely." \#00:02:16-9\# (Konrad_doctor_2: 34).}

Other layout and formal recommendations were underlining important key words to emphasize them or using arrows to highlight the need for action in relation of a phase change.

Overall, interviewees had some difficulties in the comprehension of the overall concept. This was confirmed in particular by difficulties in differentiating between the phases 'unstable' and 'deteriorating'. Interviewees focused too much on patients' status rather than on the suitability of the care plan and whether the symptom/problems had been anticipated which means phase 'deteriorating' or unexpected which means phase 'unstable.'

\section{'R: I find that difficult, this distinction, for me now as a conclusion, unstable, when suddenly something changes, when suddenly a change occurs and dete- riorating, well, increasingly, so to speak, it goes down bit by bit.' \#00:36:08-6\# (Hannah_alliedhealth_1: 171).}

These uncertainties demonstrated the relevance to emphasize the role of the care plan.

Interviewees raised the question whether changes in the circumstances of the family/carer alone are sufficient for a change of the palliative care phase. Therefore, it needs to be emphasised that according to the concept of the patient and his/her family/carer as a unit of care, palliative care phases should also be allocated corresponding to the needs of the family/carer. The only exception is the terminal phase. Even if the care plan urgently needs to be adjusted or the family/carers are increasingly burdened, the phase remains 'terminal'.

It emerged in all three rounds that the single page of phase definitions and some terms are not self-explanatory and need to be supplemented by broader information of the concept. Due to this, a manual for implementation and application has been developed. It is based on recurring statements of the interviewees (questions raised, given definitions etc.) as well as on the literature on palliative care phases. The revised German palliative care phase definitions can be found in the Additional file 4 . The developed manual can be requested from the authors.

\section{Cross-sectional study Clinician demographics}

A total of 71 clinicians participated in the study (details see Table 2). Nine participants (15.5\%) had extensive work experience in palliative care of more than 15 years. More than half $(50.7 \%)$ had less than five years of work experience in palliative care. Most participants were nurses $(57.7 \%)$, followed by doctors (29.6\%) and allied health professionals (12.7\%). Overall, 37 participants (52.1\%) did not have any experiences in assigning palliative care phases.

\section{Patient characteristics}

On average, patients were 69.9 years old and the majority (77.2\%) had a malignant disease. Gender distribution was almost balanced (Table 3).

\section{Inter-rater reliability}

Of all double assignments of palliative care phases, 237 (63.5\%) matched and 136 (36.5\%) did not match. Most disagreements $(78.7 \%)$ were referred to the combinations stable/deteriorating, stable/unstable and unstable/ deteriorating (Table 4). Seventy five point one percent of all assignments were completed within a time interval of $2 \mathrm{~h}$.

In total, the kappa value was 0.44 (95\% CI: $0.35-0.62)$ representing a moderate level of agreement (Table 5). Palliative care in-patient units differed in their level of agreement: unit 1 and unit 3 achieved a moderate agreement, the agreement in unit 2 was fair.

\section{Acceptability}

In Table 6, the indicators of acceptability are listed. Higher scores for 'degree of fit' and 'ease of assignment' were found for the phases 'stable' and 'terminal' than for the phases 'unstable' and 'deteriorating. In addition, the scores for 'degree of fit' and 'ease of assignment' were higher for agreed ratings than for non-matched ratings. Familiarity with patient's situation was low in general, but also higher for the phases 'stable' and 'terminal'.

\section{Comments by raters}

The analysis of the 42 comments given, indicated some challenges in assigning palliative care phases. However, few comments were notable (Table 7). Many comments provided by participants indicated that the concept was understood by the participants. 
Table 2 Demographic details of the clinician participants $(n=71)$

\begin{tabular}{|c|c|c|c|}
\hline & & $n=71$ & $\%$ \\
\hline \multirow[t]{6}{*}{ Age group (years) } & $18-24$ & 2 & 2.8 \\
\hline & $25-29$ & 5 & 7.0 \\
\hline & $30-39$ & 20 & 28.2 \\
\hline & $40-49$ & 18 & 25.4 \\
\hline & $50-59$ & 18 & 25.4 \\
\hline & 60 and older & 8 & 11.3 \\
\hline \multirow[t]{3}{*}{ Profession } & Doctors & 21 & 29.6 \\
\hline & Nurses & 41 & 57.7 \\
\hline & Allied health professionals & 9 & 12.7 \\
\hline \multirow[t]{3}{*}{ Sex } & Female & 51 & 71.8 \\
\hline & Male & 20 & 28.2 \\
\hline & Other & 0 & 0 \\
\hline \multirow[t]{4}{*}{ Work experience in palliative care (years) } & less than 5 & 36 & 50.7 \\
\hline & $5-9$ & 11 & 15.5 \\
\hline & $10-14$ & 15 & 21.1 \\
\hline & 15 years or more & 9 & 15.5 \\
\hline \multirow[t]{2}{*}{ Experience with phase assignment } & Yes & 34 & 47.9 \\
\hline & No & 37 & 52.1 \\
\hline
\end{tabular}

Table 3 Patient characteristics across all in-patient palliative care units

\begin{tabular}{llll}
\hline & & $\mathbf{n = 3 7 3}$ & \% \\
\hline Age group (years) & $25-54$ & 39 & 10.5 \\
& $55-64$ & 85 & 22.8 \\
& $65-74$ & 106 & 28.4 \\
& $75-84$ & 96 & 25.7 \\
Sex & $85+$ & 47 & 12.6 \\
& Female & 187 & 50.1 \\
Diagnosis & Male & 186 & 49.9 \\
& Other & 0 & 0 \\
& Malignant & 288 & 77.2 \\
& Non-Malignant & 85 & 22.8 \\
\hline
\end{tabular}

Table 4 Characteristics of ratings by two clinicians $(n=373)$

\begin{tabular}{lllr}
\hline Rating & Phase & n & \% \\
\hline Agreed assignments & stable & 142 & 37.9 \\
& unstable & 10 & 2.7 \\
& deteriorating & 45 & 12.0 \\
& terminal & 40 & 10.7 \\
Disagreed assignments & stable-deteriorating & 49 & 13.1 \\
& stable-unstable & 35 & 9.3 \\
& stable-terminal & 9 & 2.4 \\
& unstable-deteriorating & 23 & 6.1 \\
& unstable-terminal & 5 & 1.3 \\
& deteriorating-terminal & 15 & 4.0 \\
\hline
\end{tabular}

\section{Discussion}

In this study, we have developed a culturally adapted version of the Australian concept of palliative care phase and determined the inter-rater reliability of the revised German definitions. In Australia, the palliative care phase concept is very well established in specialist palliative care and is used nationwide [12]. However, in order for it to be used in other countries and their healthcare systems, it needs to be adapted to the prevailing conditions.

The results of cognitive interviewing showed that the formal translation of the phases was not fitting adequately to wording and procedures in the German specialist palliative care setting, e.g. the description of the bereavement phase or the need to use terms consistently. Moreover, some terms were not self-explanatory for the professionals and the single page of phase definitions was insufficient to convey a comprehensive understanding of the concept. These problems in understanding the concept became particularly apparent in respect of the phases 'deteriorating' and 'unstable.' Interviewees focused solely on patients' condition rather than on the suitability of the care plan and whether the symptom/problems had been anticipated or not. The observed uncertainties with single terms as well as with the overall concept emphasized the need to complement the phase definition with further information in an additional manual. Overall, the results confirmed the need to adapt the formal translation of 
Table 5 Rater agreement by in-patient palliative care unit

\begin{tabular}{|c|c|c|c|c|c|}
\hline Unit & Number of assignments & $\begin{array}{l}\text { Percentage of actual } \\
\text { agreement }\end{array}$ & Kappa & 95\% confidence interval & $\begin{array}{l}\text { Strength of } \\
\text { agreement }\end{array}$ \\
\hline 1 & 185 & 67.0 & 0.48 & $0.37-0.59$ & Moderate \\
\hline 2 & 80 & 51.2 & 0.29 & $0.13-0.45$ & Fair \\
\hline 3 & 108 & 66.7 & 0.49 & $0.39-0.52$ & Moderate \\
\hline Overall & 373 & 63.5 & 0.44 & $0.35-0.62$ & Moderate \\
\hline
\end{tabular}

Table 6 Degree of fit, ease of assignment and familiarity with patient's situation by palliative care phase and match/mismatch

\begin{tabular}{|c|c|c|c|c|c|c|}
\hline \multirow[t]{2}{*}{ Palliative care phase } & \multicolumn{2}{|c|}{ Degree of fit } & \multicolumn{2}{|c|}{ Ease of assignment } & \multicolumn{2}{|c|}{$\begin{array}{l}\text { Familiarity with patient's } \\
\text { situation }\end{array}$} \\
\hline & Mean & SD & Mean & SD & Mean & SD \\
\hline Stable & 3.24 & 0.84 & 4.22 & 0.91 & 3.00 & 1.03 \\
\hline Unstable & 2.47 & 1.23 & 3.37 & 1.06 & 2.53 & 1.06 \\
\hline Deteriorating & 2.86 & 0.90 & 3.70 & 0.97 & 2.69 & 1.12 \\
\hline Terminal & 3.61 & 0.77 & 4.46 & 0.82 & 2.92 & 1.09 \\
\hline Match & 3.29 & 0.86 & 4.23 & 0.89 & 2.94 & 1.05 \\
\hline Mismatch & 2.83 & 10.4 & 3.70 & 1.06 & 2.72 & 1.11 \\
\hline
\end{tabular}

Table 7 Comments by raters

\begin{tabular}{lll}
\hline Comment & Phase & Comments of the clinicians \\
\hline 1 & Stable & Support during the dying process, nevertheless stable phase \\
2 & Unstable & Expected, but only potential bleeding complication, therefore unstable \\
3 & Unstable & Fluctuating course, but problems were anticipated. Therefore, not unexpected, but still unstable \\
4 & Deteriorating & Caring relatives are burdened applies but does not apply to patient care \\
5 & Deteriorating & Line between deteriorating and dying unclear. Here, for example, the patient's general condi- \\
& tion has steadily deteriorated and death is likely within days \\
\hline
\end{tabular}

palliative care phases to the cultural context of the German specialist palliative care setting and consider setting specific wording/language as well as educational needs of professionals. The necessity of cultural adaptations was also reported by other studies that translated patient reported outcomes [28, 31-34].

The inter-rater reliability showed a moderate degree of agreement $(K a p p a=0.48)$ within participating centres. Compared to the Australian study [12] (kappa =0.67) the agreement was lower. Most mismatches were, as in Australia, stable/deteriorating, stable/unstable and unstable/ deteriorating combinations. The overall mean 'degree of fit' of 3.12 was comparable to the Australian data (mean 'degree of fit' of 3.28) and indicated that the developed phase definitions are appropriate to apply in Germany. In addition, all scores for 'degree of fit' and 'ease of assignment' were higher for matched ratings than for nonmatched ratings. Furthermore, the phases 'unstable' and 'deteriorating' had lower values (2.47 and 2.86) and were therefore more difficult to assign than the phases 'stable' and 'terminal' (3.37 and 3.7). The higher number of mismatches, when these phases were included, confirms this. It moreover indicates that especially 'terminal' and 'stable' phases were easier to assign and the phase description fitted better with the patient's situation. This is not surprising, as these phases are more obvious and thus easier to assign. Looking at the comments given after the assignment, the first and fifth indicate that these participants had difficulties in understanding the phase 'terminal' as they disregarded that the terminal phase overrules the other phases. Both, the second and third comment indicate that the participants have understood the concept. Nevertheless, they assigned the phase 'unstable', although they wrote that problems had been anticipated. These are aspects that must be taken into account for the education and implementation process. 
When comparing our data to the Australian data, it must be taken into account that the preconditions in both studies were different. In Australia, the palliative care phases had been introduced in 1993 and since PCOC was founded in 2005, they are firmly established and accepted across the country [10,11]. Furthermore, 55\% of the participants in Australia had more than 15 years of work experience in palliative care. The same percentage also participated in a PCOC education workshop and on the job training [12] In our study, only $12.7 \%$ of participants had more than 15 years of work experience and about half $(50.7 \%)$ less than five years. In addition, more than half of the participants $(52.1 \%)$ had no experience in assigning palliative care phases. This emphasizes that training, practice and experience is essential to apply the concept correctly and adequately. Australian data confirms this: in the first study on inter-rater reliability in 1996, the level of agreement was 0.736 and the associated kappa statistic was 0.52 , which was lower than in the study conducted in 2015 [11].

Our data also give some insights that factors beyond experience might be associated with the assignment of palliative care phases and, thus, the level of agreement. Unit 2 had greater disagreements in allocating the phases than the other two units although the characteristics of the participants including the experience with palliative care phase and patient population did not differ significantly. One reason for this could have been the lower number of cases. The analysis of the comments also indicated that some participants potentially might have understood the concept but did not follow it. This could be referred to non-acceptance of the concept and its purpose and benefits. To increase the acceptance of outcome measures, Antunes and colleagues recommend explaining the benefits in more detail, giving insight on how the instrument is constructed and discussing how the application can be handled in everyday work [35]. In this case it might be helpful to provide practice sessions and feedback, especially for the unstable and deteriorating phase. For a successful long-term implementation, these factors must be taken into account and appropriate teaching materials must be developed and included.

\section{Strengths and limitations of the study}

The strength of this study was the inclusion of multiple professions in the cognitive interviews and in the determination of the inter-rater reliability, which allowed us to gain comprehensive insights. Moreover, the interviews were conducted in several specialist palliative care settings, i.e. inpatient units, consultative and community services. Due to the integration of three settings, an instrument was developed that applies to all specialist palliative care settings in Germany. The method of cognitive interviewing has proven to be very suitable, as it reflected the views and experiences of the clinical experts and, in addition, revealed open questions concerning the concept. There are also some limitations in this study. Due to limited resources, there was no backward translation and no wider psychometric testing like validity and test-retest reliability. However, the results demonstrate that cognitive interviewing was the more important step as cultural adaptations were proven to be essential. Although the setting of Part ii) was limited to inpatient care, three units were recruited to participate, yet we cannot provide information on how it is in other settings. Unfortunately, we do not know whether the participants used the manual provided for the second part of the study and whether it was useful for them. Nor could we ascertain how the concept was appreciated, accepted, and internalised by the participants in the units. This may have varied from one unit to another.

\section{Conclusion}

Overall, the palliative care phases are suitable to use in the German specialist palliative care setting. The phases of the patients' conditions can also be identified, are applicable and a moderate inter-rater agreement has been reached. In view that outcome measures/benchmarking will play a bigger role in the future, the concept is a useful tool for this purpose. It thus contributes to further development and improvement of palliative care in Germany. However, it became clear that the concept is not easy to understand. It requires education, on-thejob training, and experience as well as the involvement of healthcare professionals to reduce resistance in order to implement it nationwide. As the implementation of new outcome measurement tools can encounter resistance in practice [36], it would be important for future research to also evaluate the process of implementation in Germany and internationally and how, for example provided teaching materials are used.

\section{Supplementary Information}

The online version contains supplementary material available at https://doi. org/10.1186/s12904-021-00825-z.

Additional file 1. COREQ Reporting Checklist

Additional file 2. Sampling frame

Additional file 3. Interview guides

Additional file 4. German version of palliative care phase definitions

Additional file 5. Australian Palliative Care Phase definitions.

Acknowledgements

The authors would like to thank the participants for their engaged participation and the PCOC organisation in Australia for the splendid support. 


\section{Authors' contributions}

$\mathrm{CB}$ and $\mathrm{FH}$ obtained the funding and concept of the study. Development of the design, interview guides and assessment sheet: EL, BG and CB. Conduction of interviews: EL and BG. First mapping of data, identification of codes and development of the coding guide: EL and BG. Coding: EL. BG second coded. EL, CB, ML, CK, FN, CO managed data collection on specialist palliative care units. Statistical analysis: BG. EL and BG drafted the manuscript. CB and $\mathrm{FH}$ critically reviewed the manuscript for important intellectual content and contributed with expertise to the discussion of results. ML, CK, FN and CO commented the draft. All authors provided critical comments on drafts of the manuscript and approved the final manuscript.

\section{Funding}

The study was financed by a private foundation that does not wish to be named publicly, but can be requested from the authors. The foundation had no role in the design of the study, the collection, analysis and interpretation of data and the writing of the manuscript. Open Access funding enabled and organized by Projekt DEAL.

\section{Availability of data and materials}

The datasets generated and/or analysed during the current study are not publicly available due [data agreement reasons: interview manuscripts cannot be anonymised entirely, the interviewees' anonymity would not be guaranteed] but are available from the corresponding author on reasonable request.

\section{Declarations}

\section{Ethics approval and consent to participate}

All methods were performed in accordance with the relevant guidelines and regulations (Declaration of Helsinki). All participants gave written informed consent. Ethical approval for both studies was sought and granted by the research ethics committee of Ludwig-Maximilians-University Munich (reference numbers 19-865 and 20-102). The PCOC organization was asked for the permission to translate and culturally adapt the palliative care phases in Germany.

\section{Consent for publication}

Participants gave written informed consent for the publication of any findings from the analysis provided that their anonymity will be preserved.

\section{Competing interests}

The authors declare that there is no conflict of interest.

\section{Author details}

1 Department, of Palliative Medicine, University Hospital, LMU Munich, Marchioninistr. 15, 81377 Munich, Germany. ${ }^{2}$ Department of Palliative Medicine, University Medical Center Goettingen, Goettingen, Germany. ${ }^{3}$ Department of Palliative Medicine, Universitätsklinikum Erlangen, CCC Erlangen-EMN, Friedrich-Alexander-Universität Erlangen-Nürnberg (FAU), Erlangen, Germany.

Received: 15 April 2021 Accepted: 24 July 2021

Published online: 14 August 2021

\section{References}

1. Radbruch L, Payne S. White paper on standards and norms for hospice and palliative care in Europe: part 1. Zeitschrift für Palliativmedizin. 2011;12(05):216-27.

2. Eagar K, Gordon R, Green J, Smith M. An Australian casemix classification for palliative care: lessons and policy implications of a national study. Palliat Med. 2004;18(3):227-33.

3. Guo P, Dzingina M, Firth AM, Davies JM, Douiri A, O'Brien SM, et al. Development and validation of a casemix classification to predict costs of specialist palliative care provision across inpatient hospice, hospital and community settings in the UK: a study protocol. BMJ Open. 2018;8(3):e020071.

4. Etkind SN, Daveson BA, Kwok W, Witt J, Bausewein C, Higginson IJ, et al. Capture, transfer, and feedback of patient-centered outcomes data in palliative care populations: does it make a difference? A systematic review. J Pain Symptom Manage. 2015;49(3):611-24.

5. Hill N. Use of quality-of-life scores in care planning in a hospice setting: a comparative study. Int J Palliat Nurs. 2002;8(11):540-7.

6. Bradshaw A, Santarelli M, Mulderrig M, Khamis A, Sartain K, Boland JW, et al. Implementing person-centred outcome measures in palliative care: an exploratory qualitative study using normalisation process theory to understand processes and context. Palliat Med. 2021;35(2):397-407.

7. Currow DC, Allingham S, Yates P, Johnson C, Clark K, Eagar K. Improving national hospice/palliative care service symptom outcomes systematically through point-of-care data collection, structured feedback and benchmarking. Support Care Cancer. 2015;23(2):307-15.

8. Dudgeon D. The impact of measuring patient-reported outcome measures on quality of and access to palliative care. J Palliat Med. 2018;21(S1):S-76-S-80.

9. Milazzo S, Hansen E, Carozza D, Case AA. How effective is palliative care in improving patient outcomes? Curr Treat Options Oncol. 2020;21(2):1-12.

10. Smith M, Firns P, editors. Palliative Care Casemix Classification--testing a model in a variety of palliative care settings--preliminary results. Proceedings of the Sixth Australian Casemix Conference; 1994.

11. Smith $M$, editor Palliative care casemix-stage 2 development: a national classification for any site of care. The 8th National Casemix Conference Commonwealth Department of Human Services and Health; 1996.

12. Masso M, Allingham SF, Banfield M, Johnson CE, Pidgeon T, Yates P, et al. Palliative care phase: inter-rater reliability and acceptability in a national study. Palliat Med. 2015;29(1):22-30.

13. Mather H, Guo P, Firth A, Davies JM, Sykes N, Landon A, et al. Phase of Illness in palliative care: cross-sectional analysis of clinical data from community, hospital and hospice patients. Palliat Med. 2017;32(2):404-12.

14. Currow DC, Eagar K, Aoun S, Fildes D, Yates P, Kristjanson LJ. Is it feasible and desirable to collect voluntarily quality and outcome data nationally in palliative oncology care? J Clin Oncol. 2008;26(23):3853-9.

15. Eagar K, Green J, Gordon R. An Australian casemix classification for palliative care: technical development and results. Palliat Med. 2004;18(3):217-26.

16. Rawlings D, Hendry K, Mylne S, Banfield M, Yates P. Using palliative care assessment tools to influence and enhance clinical practice. Home Healthcare Now. 2011;29(3):139-45.

17. Green J, Gordon R, Blanchard M, Kobel C, Eagar K. Development of AN-SNAP version 4: final report, Centre for Health Service Development, University of Wollongong. 2015.

18. Witt J, Murtagh F, de Wolf-Linder S, Higginson I, Daveson B. Introducing the outcome assessment and complexity collaborative (OACC) suite of measures-a brief introduction. Kings College London. 2014.

19. de Wolf-Linder S, Dawkins M, Wicks F, Pask S, Eagar K, Evans CJ, et al. Which outcome domains are important in palliative care and when? An international expert consensus workshop, using the nominal group technique. Palliat Med. 2019;33(8):1058-68.

20. PCOC. Time in the unstable phase - revised benchmark [Available from: https://documents.uow.edu.au/content/groups/public/@web/@chsd/@ pcoc/documents/doc/uow147037.pdf.

21. Leitlinienprogramm Onkologie (Deutsche Krebsgesellschaft DK, AWMF). Palliativmedizin für Patienten mit einer nicht-heilbaren Krebserkrankung, Langversion 2.2, 2020, AWMF-Registernummer: 128/001OL 2020 [Available from: https://www.leitlinienprogramm-onkologie.de/leitlinien/palli ativmedizin/.

22. Hodiamont F, Jünger S, Leidl R, Maier BO, Schildmann E, Bausewein C. Understanding complexity-the palliative care situation as a complex adaptive system. BMC Health Serv Res. 2019;19(1):157.

23. Von Elm E, Altman DG, Egger M, Pocock SJ, Gøtzsche PC, Vandenbroucke JP. The Strengthening the Reporting of Observational Studies in Epidemiology (STROBE) statement: guidelines for reporting observational studies. Ann Intern Med. 2007;147(8):573-7.

24. Tong A, Sainsbury P, Craig J. Consolidated criteria for reporting qualitative research (COREQ): a 32-item checklist for interviews and focus groups. Int J Qual Health Care. 2007;19(6):349-57.

25. Etikan I, Musa SA, Alkassim RS. Comparison of convenience sampling and purposive sampling. Am J Theor Appl Stat. 2016;5(1):1-4.

26. Knafl K, Deatrick J, Gallo A, Holcombe G, Bakitas M, Dixon J, et al. The analysis and interpretation of cognitive interviews for instrument development. Res Nurs Health. 2007;30(2):224-34. 
27. Beatty PC, Willis GB. Research synthesis: the practice of cognitive interviewing. Public Opin Q. 2007;71(2):287-311.

28. Beaton DE, Bombardier C, Guillemin F, Ferraz MB. Guidelines for the process of cross-cultural adaptation of self-report measures. Spine. 2000;25(24):3186-91.

29 Landis JR, Koch GG. The measurement of observer agreement for categorical data. Biometrics. 1977;33:159-74.

30. Connolly AM, Burns SJ, Allingham SF, Foskett LM, Clapham SP, Daveson BA. Patient outcomes in palliative care in Australia: national report for January-June 2019. 2019.

31. Grove WDA, Martin M, Eremenco S, McElroy S, Verjee-Lorenz A, Erikson P. Principles of good practice for the translation and cultural adaptation process for patient-reported outcomes (PRO) measures: report of the ISPOR Task Force for Translation and Cultural Adaptation. Value Health. 2005;8(2):94-104.

32. Ross L, Neergaard MA, Petersen MA, Groenvold M. Measuring the quality of end-of-life care: development, testing, and cultural validation of the Danish version of views of informal carers' evaluation of services-short form. Palliat Med. 2018;32(4):804-14.

33. Bæksted C, Nissen A, Pappot H, Bidstrup PE, Mitchell SA, Basch E, et al. Danish translation and linguistic validation of the US National Cancer
Institute's patient-reported outcomes version of the common terminology criteria for adverse events (PRO-CTCAE). J Pain Symptom Manage. 2016;52(2):292-7.

34. Hodiamont F, Hock H, Ellis-Smith C, Evans C, de Wolf-Linder S, Jünger S, et al. Culture in the spotlight-cultural adaptation and content validity of the integrated palliative care outcome scale for dementia: a cognitive interview study. Palliat Med. 2021;35(5):962-71.

35 Antunes B, Harding R, Higginson IJ, EUROIMPACT. Implementing patientreported outcome measures in palliative care clinical practice: a systematic review of facilitators and barriers. Palliat Med. 2014;28(2):158-75.

36 Murtagh FE, Pinto C, Bristowe K, Witt J, Davies JM, de Wolf-Linder S, et al. Perspectives of patients, family caregivers and health professionals on the use of outcome measures in palliative care and lessons for implementation: a multi-method qualitative study. Ann Palliat Med. 2018;7(s3):S137-50.

\section{Publisher's Note}

Springer Nature remains neutral with regard to jurisdictional claims in published maps and institutional affiliations.
Ready to submit your research? Choose BMC and benefit from:

- fast, convenient online submission

- thorough peer review by experienced researchers in your field

- rapid publication on acceptance

- support for research data, including large and complex data types

- gold Open Access which fosters wider collaboration and increased citations

- maximum visibility for your research: over $100 \mathrm{M}$ website views per year

At BMC, research is always in progress.

Learn more biomedcentral.com/submissions 